\title{
Laser Capture Microdissection of Uredinia Formed by Melampsora larici-populina Revealed a Transcriptional Switch Between Biotrophy and Sporulation
}

\author{
Stéphane Hacquard, Christine Delaruelle, Valérie Legué, Emilie Tisserant, Annegret Kohler, \\ Pascal Frey, Francis Martin, and Sébastien Duplessis \\ Unité Mixte de Recherche 1136 INRA/Nancy Université 'Interactions Arbres/Micro-organismes', INRA Nancy, F-54280 \\ Champenoux, France
}

Submitted 17 May 2010. Accepted 8 June 2010.

\begin{abstract}
The foliar rust caused by the basidiomycete Melampsora larici-populina is the main disease affecting poplar plantations in Europe. The biotrophic status of rust fungi is a major limitation to study gene expression of cell or tissue types during host infection. At the uredinial stage, infected poplar leaves contain distinct rust tissues such as haustoria, infection hyphae, and uredinia with sporogenous hyphae and newly formed asexual urediniospores. Laser capture microdissection (LCM) was used to isolate three areas corresponding to uredinia and subjacent zones in the host mesophyll for expression analysis with $M$. laricipopulina whole-genome exon oligoarrays. Optimization of tissue preparation prior to LCM allowed isolation of RNA of good integrity for genome-wide expression profiling. Our results indicate that the poplar rust uredinial stage is marked by distinct genetic programs related to biotrophy in the host palisade mesophyll and to sporulation in the uredinium. A strong induction of transcripts encoding small secreted proteins, likely containing rust effectors, is observed in the mesophyll, suggesting a late maintenance of suppression of host defense in the tissue containing haustoria and infection hyphae. On the other hand, cell cycle and cell defense rescue transcripts are strongly accumulated in the sporulation area. This combined LCM-transcriptomic approach brings new insights on the molecular mechanisms underlying urediniospore formation in rust fungi.
\end{abstract}

The foliar rust caused by the basidiomycete fungus Melampsora larici-populina is the main disease affecting poplar in Europe, causing severe damages in plantations (Gérard et al. 2006). At present, almost all planted poplar cultivars are susceptible to $M$. larici-populina, and sustainability of newly selected resistances requires a better understanding of the molecular mechanisms underlying Populus-Melampsora spp. interaction. The recent sequencing of the $M$. larici-populina genome is a great opportunity to identify loci coding for the arsenal developed by the rust fungus to penetrate and exploit its host (Duplessis et al. 2009). M. larici-populina has a complex bio-

Corresponding author: S. Duplessis; Telephone: +33 3833940 13; E-mail: duplessi@nancy.inra.fr

* The $\boldsymbol{e}$-Xtra logo stands for "electronic extra" and indicates that one supplementary table and one supplementary figure are published online. logical lifecycle, performing sexual reproduction on an alternate host (Larix spp.), whereas polycyclic production of asexual urediniospores occurs during summer on poplar trees, leading to severe epidemics (Barrès et al. 2008). The fungus penetrates through stomata on the abaxial epidermis of poplar leaves between 2 and $6 \mathrm{~h}$ after a spore lands on a leaf surface (Rinaldi et al. 2007). A drastic increase in fungal biomass is observed at $96 \mathrm{~h}$ postinfection (hpi) inside parenchyma cells after the formation of haustoria (Rinaldi et al. 2007). This infection structure, involved in the redirection of host metabolism and the suppression of host defenses, allows the establishment of a successful biotrophic relationship (Heath 1997; Voegele et al. 2009). By $168 \mathrm{hpi}$, orange pustules corresponding to uredinia release urediniospores on the leaf surface to achieve further infection of poplar leaves.

The obligate biotroph status of rust fungi is a limitation to the study of gene expression in structures involved in biotrophic growth or sporulation stage because rust cannot be cultivated outside of their hosts. Most of the knowledge gained on rust gene expression in planta derived from sequencing of expressed sequence tags (EST) from haustorial structures or infected plant tissues (Hahn and Mendgen 1997; Thara et al. 2003; Broeker et al. 2006; Catanzariti et al. 2006; Feau et al. 2007; Puthoff et al. 2008; Yin et al. 2009). Identification of genes specifically expressed during the biotrophic phase was reported in the bean rust Uromyces fabae such as the thiamine biosynthesis genes THII and THI2 (Sohn et al. 2000), the amino-acid transporter AAT2 and the sugar transporter HXT1 (Hahn et al. 1997; Voegele et al. 2001), or the rust-transferred protein 1 RTP1 (Kemen et al. 2005). In the flax rust Melampsora lini, haustorially expressed secreted proteins (HESP) were reported as highly enriched for avirulence elicitors (Dodds et al. 2004; Catanzariti et al. 2006, 2010). In Uromyces appendiculatus, a large number of EST confirmed the importance of secreted proteins, primary metabolism, and nutrient uptake in haustorial structures (Puthoff et al. 2008). In contrast to the knowledge of molecular events related to rust invasion in plant hosts, nothing is known about gene networks underlying spore formation in rust fungi. The complexity of fungal structures at late infection stages (i.e., host tissues containing haustoria, infection hyphae, sporogenous hyphae, and newly formed spores) is a major limitation to identifying genes specifically involved in sporulation.

Laser capture microdissection (LCM) is a powerful tool to isolate populations of cells from heterogeneous tissues and 
offers new possibilities to explore transcript expression analysis on specific cells or tissues. LCM has been successfully used to study gene expression in different plant tissues such as epidermal cells, shoot meristem tissues, and root cap tissues
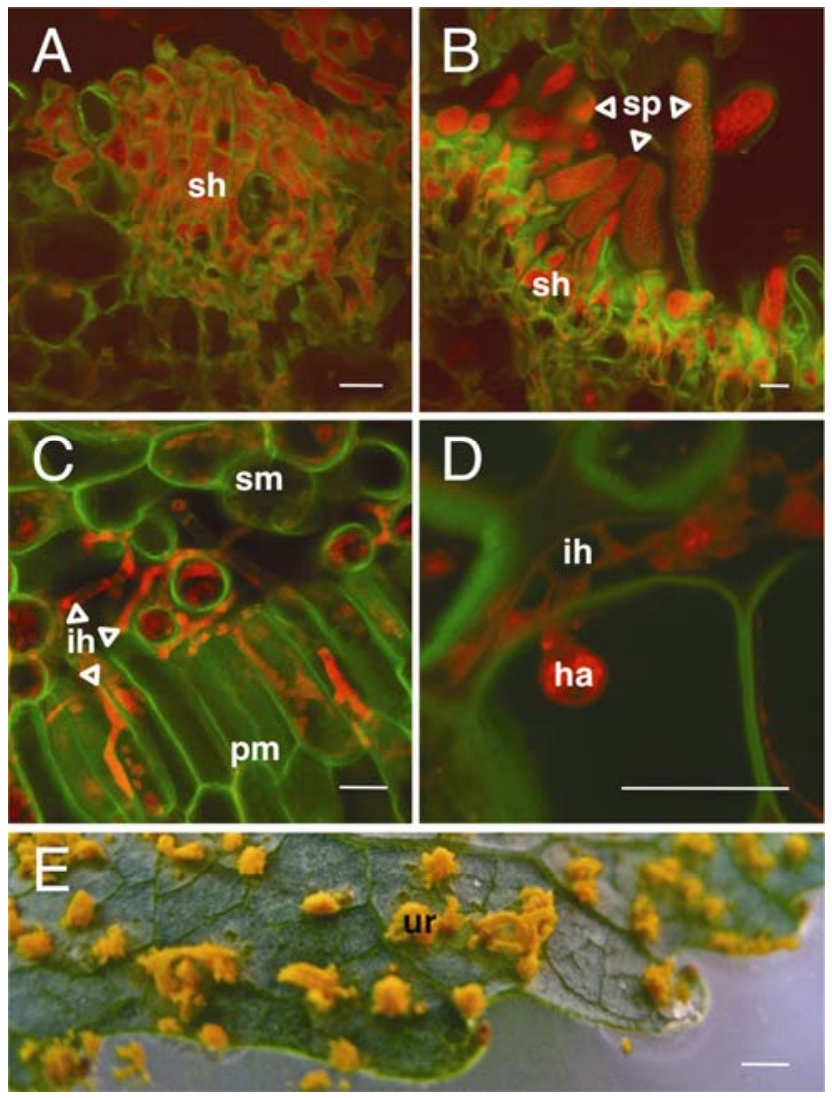

Fig. 1. Development of uredinia from Melampsora larici-populina 98AG31 in the susceptible Populus trichocarpa $\times$ P. deltoides cv. Beaupré. A through D, Confocal laser scanning microscopy images of fungal structures in planta at uredinial stage using Uvitex $2 \mathrm{~B}$ staining plant and fungal cell walls (green) and propidium iodide staining fungal material (red). A, Early and B, mature uredinium formed after 96 and $168 \mathrm{~h}$ postinfection (hpi). C, Infection hyphae and $\mathbf{D}$, haustorium colonizing spongy and palisade mesophyll at 168 hpi. Pictures were taken using a $\times 100$ objective lens; scale bar represents $5 \mu \mathrm{m}$. E, Macroscopic view of mature uredinia. Bar represents $1 \mathrm{~mm}$; $\mathrm{sh}=$ sporogenous hyphae, $\mathrm{sp}=$ spores, $\mathrm{ih}=$ infection hyphae, ha $=$ haustorium, $\mathrm{sm}=$ spongy mesophyll, $\mathrm{pm}=$ palisade mesophyll, ur $=$ uredinium.
(Nakazono et al. 2003; Jiang et al. 2006; Brooks et al. 2009). So far, only a few studies have reported the use of LCM to study plant-microbe interactions (Balestrini et al. 2009) such as those between plants and nematodes (Ramsay et al. 2004; Klink et al. 2007; Ithal et al. 2007), arbuscular mycorrhizal fungi (Balestrini et al. 2007; Gomez and Harrison 2009), and pathogenic fungi (Tang et al. 2006; Tremblay et al. 2009; Chandran et al. 2010). An LCM-based approach allowed collecting maize stalk cells associated with Colletotrichum graminicola hyphae at early stage of infection and microarray analysis led to the identification of several transcripts highly accumulated and potentially involved in pathogenesis (Tang et al. 2006). In a study conducted on soybean infected by the rust fungus Phakopsora pachyrhizi, RNA isolation through LCM from uredinia allowed cDNA library construction and access to a few rust unisequences (Tremblay et al. 2009). More recently, microdissection of infection sites from Arabidopsis leaves challenged by the powdery mildew Golovinomyces orontii helped in identifying downstream elements of the plant defense response not previously detected through whole-leaf transcriptome analysis (Chandran et al. 2010).

In this study, we successfully used LCM to dissect three distinct areas from poplar leaves infected by M. larici-populina at the uredinial stage. Using this strategy, we were able to separate fungal sporulation and fungal infection tissues. High-quality total RNA were isolated and amplified from these areas to assess rust transcript profiles through transcriptome analysis using M. larici-populina whole-genome exon oligoarrays and reverse-transcription quantitative polymerase chain reaction (RT-qPCR).

\section{RESULTS}

\section{Development of $M$. larici-populina uredinia in poplar leaves.}

M. larici-populina uredinia development was visualized in planta at 96 and 168 hpi using laser-scanning confocal microscopy. Primordia of uredinia containing initial sporogenous hyphae were observed at 96 hpi inside spongy mesophyll (Fig. 1A) whereas mature uredinia, from which newly formed dikaryotic urediniospores are released, were observed at 168 hpi (Fig. 1B). In addition, these stages were marked by a massive accumulation of fungal infection hyphae (Fig. 1C), and the presence of many haustoria was also noticeable (Fig. 1D) in both spongy and palisade mesophylls. At $168 \mathrm{hpi}$, uredinia emerged as yellow-orange pustules on the abaxial leaf surface

\section{Before LCM}

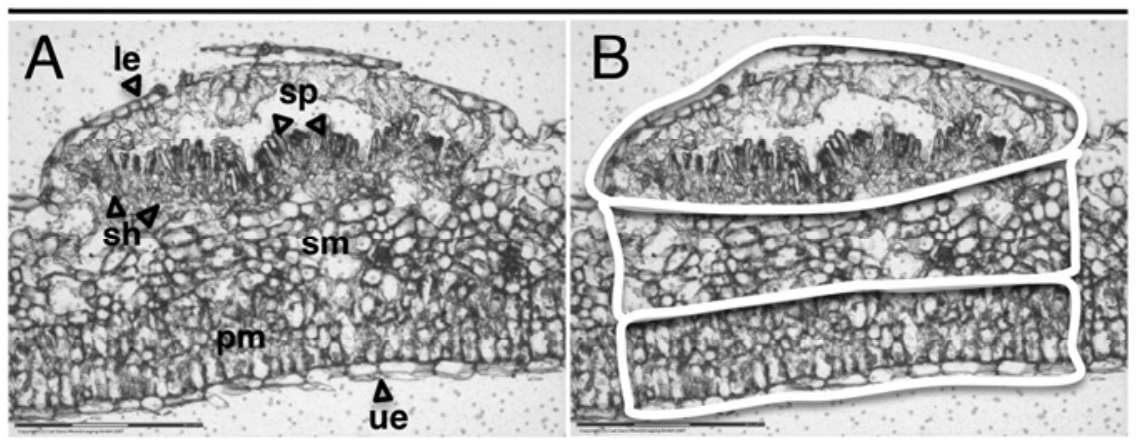

After LCM

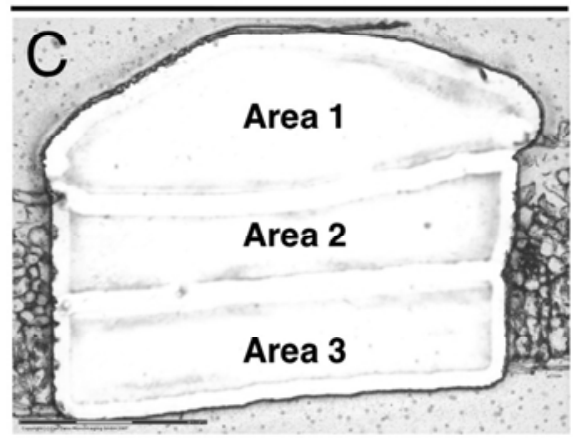

Fig. 2. Laser capture microdissection (LCM) of an uredinium formed by Melampsora larici-populina strain 98AG31 on the susceptible poplar cv. Beaupré. A, Transversal section of an uredinium; B, selection of areas for LCM; and $\mathbf{C}$, section after laser capture of the three selected areas. Area 1 , subepidermal $M$. larici-populina uredinium below poplar abaxial surface containing urediniospores and sporogenous hyphae; area 2, poplar leaf spongy mesophyll containing infection hyphae and haustoria; and area 3, poplar leaf palisade mesophyll containing M. larici-populina infection hyphae and haustoria. Pictures were taken using a $\times 40$ objective lens; scale bar represents $150 \mu \mathrm{m} ; \mathrm{sh}=$ sporogenous hyphae, $\mathrm{sp}=$ spores, $\mathrm{sm}=$ spongy mesophyll, pm $=$ palisade mesophyll, le $=$ lower leaf epidermis, ue $=$ upper leaf epidermis. 
of poplar and led to a massive production of asexual urediniospores (Fig. 1E).

\section{Optimization of RNA isolation from LCM uredinia.}

Ethanol-acetic acid (EAA) fixation has been reported to maintain histological integrity while enabling good RNA yield recovery (Kerk et al. 2003) and has been successfully used for LCM and microarray analysis of plant tissues (Nakazono et al. 2003; Casson et al. 2008). EAA-fixed and sectioned uredinia are shown before (Fig. 2A and B) and after (Fig. 2C) laser capture of area 1, 2, and 3 (i.e., spores and sporogenous hyphae, fungal infection tissues in spongy mesophyll, and fungal infection tissues in palisade mesophyll, respectively) (Fig. 2B). Good preservation of plant and fungal cell structures were obtained from EAA-fixed, paraffin-embedded sections but initial efforts to isolate intact RNA from laser-captured areas were unsuccessful. Using the conventional method of slide mounting, where paraffin ribbons were floated onto a bead of diethylpyrocarbonate (DEPC) water and mounted onto a slide, strong RNA degradation was observed for the different areas as revealed by the absence of ribosomal (r)RNA peaks on RNA electrophoresis profiles (Fig. 3A). When paraffin ribbons were directly transferred onto a microscope slide without water and slide drying, a drastic increase of RNA integrity was observed (Fig. 3B). A moderate degradation of RNA was still observed as revealed by the attenuated signal of the $28 \mathrm{~S}$ ribosomal subunits of rRNA. In order to improve RNA integrity, we used a $37^{\circ} \mathrm{C}$ melting point paraffin instead of conventional paraffin at $58^{\circ} \mathrm{C}$ to prevent exposition of RNA molecules to high temperatures during paraffin impregnation of samples. Using this low-melting-point paraffin coupled with a direct transfer of paraffin ribbons onto microscope slides, two distinct peaks of rRNA were observed for each sampled area on electrophoresis profile, indicating improved RNA integrity after LCM (Fig. 3C; Supplementary Fig. 1A). Less than $5 \mathrm{ng}$ of total RNA were isolated from the three LCM uredinia areas and more than $4 \mu \mathrm{g}$ of amplified RNA (aRNA) were produced for all samples through linear amplification (Nakazono et al. 2003; Chandran et al. 2010), enabling proper synthesis of cDNA amounts to perform labeling and array hybridization.

\section{Gene expression profiling of LCM fungal tissues.}

M. larici-populina whole-genome exon oligoarrays were used to measure transcripts expression in the three areas isolated from uredinia. Among the 15,388 genes analyzed on the oligoarrays, 9,650 (63\%) were expressed above background level in at least one of the different areas. In detail, 8,145, 7,786, and 7,288 transcripts were detected in area 1,2, and 3, respectively. Few differentially expressed transcripts ( $t$ test, $P$ value $<0.05$, fold-change $>3$ ) were detected between area 2 and 1 or area 2 and 3 (0 and 56 transcripts respectively; data not shown). In contrast, a strong proportion of transcripts were differentially accumulated between area 1 and 3, suggesting a continuum of transcript expression between the three sampled areas in uredinia. In total, 542 transcripts were induced in area 3 compared with area 1 , whereas 762 were induced in area 1 compared with area 3 . The comparison of transcript profiles between these two contrasted areas at the uredinial stage allowed us to gain insights into the genes associated with biotrophy (area 3) and sporulation (area 1).

\section{Poplar rust biotrophy-related transcripts.}

Among the 542 M. larici-populina transcripts upregulated in area 3 compared with area 1, 117 shared similarities with known proteins and were assigned to functional categories (Table 1) based on the Functional Catalogue (FunCat) scheme (Ruepp et al. 2004) to decipher molecular mechanisms under- lying biotrophic growth. Six transcripts encoding M. lini HESP homologs previously identified in haustoria during flax infection (Catanzariti et al. 2006) (JGI [Joint Genome Institute] protein ID nos. 64764, 58916, 103805, 110232, 71126, and 93569) were gradually expressed in spongy mesophyll toward palisade mesophyll and showed inductions ranking between seven- and 90-fold compared with the sporulation area (Table 1). Two of them were identified among the 25 most highly induced $M$. larici-populina transcripts ( $>80$-fold) in area 3 compared with area 1 (Table 2). Interestingly, 19 of these 25 most highly upregulated transcripts encoded secreted proteins of less than 300 amino acids (small secreted proteins [SSP]) and most of them were lineage specific but of unknown function. The most highly induced transcript (JGI protein ID no. 106078; 400-fold induction) encoded a 137-amino-acid cysteine-rich SSP with one ortholog in the wheat stem rust Puccinia graminis f. sp. tritici genome and no ortholog in other fungi (Table 2). Induction of expression of transcripts related to lipid or polysaccharide degradation such as cutinase (JGI protein ID no. 123735), lipases (JGI protein ID nos. 110949 and 106095), and $\beta$-glycosidase (JGI protein ID no. 91623) was observed in the biotrophic area (Table 1), indicating that the fungus might still degrade the host cell wall at the uredinial stage. Several enzymes involved in carbohydrate metabolism were also strongly induced in the biotrophic area ( $>10$-fold) such as an invertase (JGI protein ID no. 44167), able to cleave sucrose from the host plant cell in glucose and fructose. Transcripts encoding sugar transporters (JGI protein ID nos. 38418 and 85306), an amino acid permease (JGI protein ID no. 34045), or an oligopeptide transporter (JGI protein ID no. 105630) were also highly induced in the biotrophic area (more than sixfold), highlighting the importance of nutrients uptake in the host mesophyll. Interestingly, the two most induced transporter transcripts (JGI protein ID nos. 38418 and 34045 ), with 31.1- and 12.1-fold changes, respectively, are homologs of the $U$. fabae hexose transporter HXT1 and amino acid permease AAT2 previously described for their expression restricted to haustoria (Hahn et al. 1997; Voegele et al. 2001). In addition, exocytosis- and cellular-trafficking-related transcripts (JGI protein ID nos. 95032, 47066, and 103049) were also

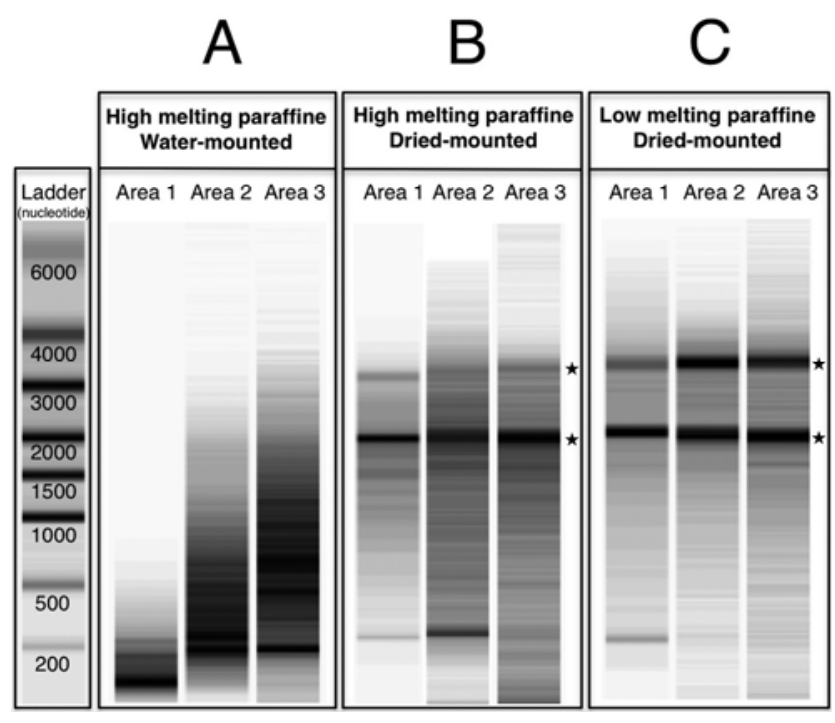

Fig. 3. Electrophoretic profiles of total RNA isolated from laser microdissected areas 1, 2, and 3 using different sample preparation methods. A, Sample impregnation using high-melting point paraffin and water mounted on the slide; $\mathbf{B}$, sample impregnation using high-melting point paraffin and dry mounted on the slide; and $\mathbf{C}$, sample impregnation using low-melting point paraffin and dry mounted on the slide. Stars indicate ribosomal RNA subunits. 
upregulated, consistent with an intense cellular transport activity in the biotrophic area. Several transcripts involved in protein degradation were also differentially expressed in area 3 compared with area 1, such as an ubiquitin-conjugating enzyme (JGI protein ID no. 41986) and a RING-finger-containing ubiquitin ligase (JGI protein ID no. 118355) with 5.5- and fivefold regulation, respectively. Moreover, two proteases (JGI protein ID nos. 69042 and 66970) acting in peptide bonds hydrolysis were upregulated 13.5- and 9.1-fold, respectively, suggesting a strong activation of fungal proteasome and proteolysis inside palisade mesophyll at late uredinial stage.

\section{Poplar rust sporulation-related transcripts.}

Among the 762 transcripts upregulated in area 1 compared with area 3, 381 showed homologies with known proteins and were assigned to functional cellular categories in order to identify gene networks associated with urediniospore formation (Table 3). An important proportion of transcripts induced in the sporulation area encode detoxification enzymes such as cytosolic $\mathrm{Cu} / \mathrm{Zn}$ superoxide dismutases (JGI protein ID nos. 72564 and
72563), peroxidases (JGI protein ID nos. 87334 and 94172), and a cytochrome P450 (JGI protein ID no. 76380), suggesting cellular protection against oxygen-derived free radicals during sporogenesis. Nine transcripts related to cell cycle control and encoding a centrin 3, septin, M-phase inducer phosphatase, and DNA replication initiation factor cdc 45 were also upregulated in area 1, highlighting the high rate of cell division in the sporulation area compared with the biotrophic area. In addition, DNA replication-, recombination-, and repair-related transcripts were strongly upregulated, consistent with cell division activity. Interestingly, most of the genes involved in cell division and detoxification were among the 25 most highly upregulated transcripts (>90-fold) in the sporulation area compared with the biotrophic area (Table 4). Transcripts encoding lipid metabolism enzymes, such as a squalene synthase (86.7-fold induction, JGI protein ID no. 94543) involved in sterol biosynthesis pathway, and three enzymes showing lipase activity, such as a phospholipase (60.4fold induction, JGI protein ID no. 59333), an epoxide hydrolase (39.2-fold induction, JGI protein ID no. 123933), and a lipase (31.1-fold induction, JGI protein ID no. 63115), were observed

Table 1. Selected Melampsora larici-populina genes presenting transcript induction in the palisade mesophyll (area 3) versus sporogenous (area 1) microdissected structures, assessed by whole-genome expression oligoarrays and categorized according to their cellular category (Functional Catalogue)

\begin{tabular}{|c|c|c|c|c|c|c|}
\hline \multirow[b]{3}{*}{ Protein ID $^{b}$} & \multirow[b]{3}{*}{ Putative function or feature } & \multicolumn{5}{|c|}{ Uredinia laser capture microdissection $^{a}$} \\
\hline & & \multicolumn{3}{|c|}{ Expression level } & \multicolumn{2}{|c|}{ Expression ratio } \\
\hline & & Area1 & Area2 & Area3 & Area3/Area1 & $\boldsymbol{P}$ \\
\hline & Subcellular localization & & & & & \\
\hline 64764 & Small secreted protein (hesp-376 homology) & 15 & 185 & 1,363 & 90.0 & 0.012 \\
\hline 58916 & Small secreted protein (hesp-C63 homology) & 15 & 246 & 1,247 & 85.7 & 0.010 \\
\hline 103805 & Small secreted protein (hesp-270 homology) & 109 & 2,994 & 4,509 & 41.5 & 0.010 \\
\hline 110232 & Small secreted protein (hesp-897 homology) & 53 & 300 & 1,512 & 28.3 & 0.042 \\
\hline 71126 & Small secreted protein (hesp-C49 homology) & 355 & 4,389 & 8,691 & 24.4 & 0.023 \\
\hline \multirow[t]{3}{*}{93569} & Small secreted protein (hesp-417 homology) & 5,665 & 18,108 & 40,009 & 7.0 & 0.033 \\
\hline & Metabolism & & & & & \\
\hline & Lipid & & & & & \\
\hline 123735 & Cutinase & 88 & 2,311 & 6,193 & 70.2 & 0.011 \\
\hline 110949 & Lipase B & 53 & 649 & 2,338 & 44.0 & 0.020 \\
\hline 106095 & Lysophospholipase A & 88 & 1,161 & 2,659 & 30.0 & 0.025 \\
\hline 87140 & Polyprenyl synthetase & 22 & 36 & 349 & 16.0 & 0.046 \\
\hline \multirow[t]{2}{*}{72337} & $\alpha / \beta$ hydrolase & 553 & 1,663 & 2,822 & 5.1 & 0.039 \\
\hline & Carbon & & & & & \\
\hline 53785 & Ribokinase & 24 & 263 & 1,020 & 42.7 & 0.018 \\
\hline 44167 & $\beta$-Fructosidase (invertase) (glycosyl hydrolase family 32) & 417 & 1,377 & 4,421 & 10.6 & 0.023 \\
\hline 29139 & Phosphoribosylglycinamide formyltransferase & 470 & 1,537 & 4,720 & 10.0 & 0.018 \\
\hline \multirow[t]{2}{*}{91623} & $\beta$-Glycosidase (glycosyl hydrolase family 5) & 30 & 54 & 205 & 6.8 & 0.034 \\
\hline & Vitamin & & & & & \\
\hline \multirow[t]{2}{*}{79837} & Riboflavin biosynthesis protein & 155 & 490 & 874 & 5.6 & 0.044 \\
\hline & Redox & & & & & \\
\hline 86038 & Oxidoreductase, 2OG-Fe(II) oxygenase family & 408 & 4,197 & 10,964 & 26.8 & 0.039 \\
\hline 90083 & Indoleamine 2,3-dioxygenase & 142 & 1,324 & 3,357 & 23.6 & 0.049 \\
\hline 63255 & NAD dependent epimerase/dehydratase & 72 & 666 & 1,502 & 20.8 & 0.031 \\
\hline 114173 & Aldo/keto reductase & 794 & 9,026 & 15,541 & 19.5 & 0.037 \\
\hline 93258 & Oxidoreductase 2OG-Fe(II) oxygenase family & 131 & 837 & 1,273 & 9.7 & 0.047 \\
\hline 33839 & FAD dependent oxidoreductase & 686 & 4,556 & 5,160 & 7.5 & 0.030 \\
\hline 109018 & Glutaredoxin & 207 & 653 & 1,551 & 7.4 & 0.036 \\
\hline 84159 & NAD dependent epimerase/dehydratase & 204 & 644 & 1,433 & 7.0 & 0.013 \\
\hline 33377 & Short-chain dehydrogenase/reductase & 1,197 & 6,383 & 7,263 & 6.0 & 0.041 \\
\hline 103191 & Oxidoreductase, 2OG-Fe(II) oxygenase family & 1,028 & 3,604 & 5,722 & 5.5 & 0.032 \\
\hline \multirow[t]{2}{*}{25325} & D-arabinono-1,4-lactone oxidase & 11 & 16 & 57 & 5.1 & 0.020 \\
\hline & Cellular transport, transport facilitation & & & & & \\
\hline 38418 & HXT1p Sugar transporter & 29 & 329 & 901 & 31.1 & 0.014 \\
\hline 34045 & Amino acid permease AAT2 & 34 & 90 & 415 & 12.1 & 0.039 \\
\hline 85306 & Sugar transporter-MFS monosaccharide transporter & 213 & 313 & 2,315 & 10.8 & 0.016 \\
\hline 95032 & Exocyst complex component, $\mathrm{sec} 3$ subunit & 13 & 17 & 112 & 8.6 & 0.036 \\
\hline 47066 & Clathrin assembly protein & 178 & 168 & 1,179 & 6.6 & 0.029 \\
\hline 105630 & Oligopeptide transporter & 121 & 458 & 792 & 6.5 & 0.040 \\
\hline \multirow[t]{2}{*}{103049} & Got1-like vesicle transport protein & 42 & 113 & 237 & 5.6 & 0.013 \\
\hline & & & & & \multicolumn{2}{|c|}{ (continued on next page) } \\
\hline
\end{tabular}


in the sporulation area (Table 3). Other enzymes involved in carbohydrate degradation, such as $\alpha$-glycosidase (JGI protein ID nos. 92210), $\beta$-glycosidases (JGI protein ID nos. 116147 and 55983), and $\alpha$-L-arabinofuranosidase (JGI protein ID no. 107307), also showed transcript induction during sporogenesis. In contrast with the biotrophic area, genes involved in nucleotide catabolism, such as ribonucleases (JGI protein ID nos. 117154 and 54248) and an endonuclease (JGI protein ID no. 26899), were strongly induced in the sporulation area, indicating a strong turnover of nucleic acids. Several transporters were specifically detected during urediniospores formation. The most induced encoded a GDP-fucose transporter (JGI protein ID no. 49361) that showed a 93-fold induction. MFS permeases (JGI protein ID nos. 94938 and 25355), an amino acid permease (JGI protein ID no. 49500), and an oligopeptide transporter (JGI protein ID no. 94692) were among the highly induced transcripts (>30-fold), indicating strong metabolite trafficking concomitant with urediniospore synthesis. In contrast with the strong proportion of SSP identified among the most highly induced transcripts in the biotrophic area (Tables 1 and 2), one M. lini HESP homo- log was induced in the sporulation tissues (Table 3) and only five SSP were identified among the 25 most highly induced transcripts (>80-fold) in the sporulation area (Table 4), suggesting the preferential role of SSP during the biotrophic growth phase.

\section{Validation of differential gene expression profiles.}

The expression level of 29 transcripts encoding $M$. laricipopulina SSP and known rust protein homologs or that showed a preferential expression pattern in area 1 or 3 was assessed by RT-qPCR. A linear correlation $\left(R^{2}=0.96\right)$ was observed between expression profiles measured by RT-qPCR and oligoarrays validating the transcriptomic approach (Fig. 4). The slope of the regression line was close to unity (0.86), indicating a minimal variation in expression data and consistency between both approaches.

\section{DISCUSSION}

As noncultivable organisms, obligate biotrophic fungi are dependent on their host to achieve their growth and develop-

Table 1. (continued from preceding page)

\begin{tabular}{|c|c|c|c|c|c|c|}
\hline \multirow[b]{3}{*}{ Protein ID $^{b}$} & \multirow[b]{3}{*}{ Putative function or feature } & \multicolumn{5}{|c|}{ Uredinia laser capture microdissection $^{a}$} \\
\hline & & \multicolumn{3}{|c|}{ Expression level } & \multicolumn{2}{|c|}{ Expression ratio } \\
\hline & & Area1 & Area2 & Area3 & Area3/Area1 & $\boldsymbol{P}$ \\
\hline & Protein fate (folding, modification, destination) & & & & & \\
\hline 69042 & Pepsin & 741 & 9,008 & 10,207 & 13.5 & 0.011 \\
\hline 66970 & Cysteine proteases & 24 & 64 & 228 & 9.1 & 0.048 \\
\hline 41986 & Ubiquitin-conjugating enzyme E2 & 990 & 2,606 & 5,531 & 5.5 & 0.035 \\
\hline \multirow[t]{2}{*}{118355} & C3HC4 type RING finger containing ubiquitin ligase & 1,193 & 3,193 & 6,042 & 5.0 & 0.013 \\
\hline & Transcription & & & & & \\
\hline 108564 & GCN5-related N-acetyltransferase & 20 & 73 & 575 & 28.7 & 0.025 \\
\hline 107345 & $\mathrm{C} 2 \mathrm{H} 2$-type $\mathrm{Zn}$ finger protein & 175 & 2,448 & 2,377 & 13.5 & 0.021 \\
\hline 74108 & Transcriptional regulator Prz1 & 1,147 & 4,880 & 11,866 & 10.3 & 0.016 \\
\hline 94759 & $\mathrm{C} 2 \mathrm{H} 2$-type $\mathrm{Zn}$ finger protein 7 & 282 & 3,356 & 2,585 & 9.1 & 0.024 \\
\hline \multirow[t]{2}{*}{39532} & Transcription elongation factor & 627 & 1,579 & 3,293 & 5.2 & 0.027 \\
\hline & Cellular communication or signal transduction mechanism & & & & & \\
\hline 106239 & NUDIX hydrolase & 44 & 392 & 991 & 22.3 & 0.010 \\
\hline 94327 & Protein kinase AGC family & 23 & 30 & 165 & 7.3 & 0.039 \\
\hline \multirow[t]{2}{*}{43665} & Response regulator receiver & 682 & 1,908 & 4,450 & 6.5 & 0.048 \\
\hline & Cell rescue, defense, and virulence & & & & & \\
\hline 40544 & Survival protein SurE & 844 & 1,810 & 13,302 & 15.7 & 0.010 \\
\hline \multirow[t]{2}{*}{106535} & Heat shock protein & 304 & 755 & 1,554 & 5.1 & 0.018 \\
\hline & Cell cycle and DNA processing & & & & & \\
\hline 60363 & DNA topoisomerase I & 27 & 69 & 349 & 13.1 & 0.034 \\
\hline \multirow[t]{2}{*}{47226} & G1 Cyclin & 472 & 2,140 & 3,863 & 8.1 & 0.028 \\
\hline & Protein synthesis & & & & & \\
\hline 30347 & Ribosomal protein $\mathrm{S} 8$ & 30 & 62 & 418 & 13.8 & 0.038 \\
\hline \multirow[t]{2}{*}{37443} & Diphthine synthase & 618 & 531 & 3,279 & 5.3 & 0.020 \\
\hline & Biogenesis of cellular components & & & & & \\
\hline 27318 & Cell wall protein & 23 & 78 & 248 & 10.6 & 0.030 \\
\hline 95757 & Proteophosphoglycan 5 & 35 & 62 & 277 & 7.9 & 0.040 \\
\hline \multirow[t]{2}{*}{64466} & Proteophosphoglycan ppg4 & 20 & 42 & 123 & 6.1 & 0.038 \\
\hline & Transposable elements, viral and plasmid proteins & & & & & \\
\hline 88937 & Transposase & 42 & 110 & 514 & 12.2 & 0.048 \\
\hline \multirow[t]{2}{*}{94469} & Transposable element & 14 & 22 & 75 & 5.2 & 0.048 \\
\hline & Energy & & & & & \\
\hline 93294 & Malate dehydrogenase & 485 & 986 & 3,429 & 7.0 & 0.042 \\
\hline 95852 & Malate dehydrogenase, NAD-dependent & 40 & 73 & 235 & 5.9 & 0.014 \\
\hline \multirow[t]{2}{*}{65530} & Electron transport complex & 12 & 45 & 72 & 5.8 & 0.031 \\
\hline & Protein with binding function or cofactor requirement & & & & & \\
\hline 105154 & Phosphatidylethanolamine-binding protein & 200 & 2,567 & 13,666 & 68.4 & 0.013 \\
\hline 66416 & Zinc finger SWIM domain-containing protein & 21 & 37 & 184 & 8.9 & 0.049 \\
\hline 62481 & Glycine-rich RNA binding protein & 1,682 & 8,050 & 12,280 & 7.3 & 0.021 \\
\hline \multirow[t]{2}{*}{38287} & Phosphatidylethanolamine-binding protein & 34 & 44 & 234 & 6.8 & 0.046 \\
\hline & Unclassified proteins & & & & & \\
\hline 28849 & Histidine-rich protein & 21 & 49 & 280 & 13.5 & 0.039 \\
\hline 93926 & Sporozoite surface protein & 22 & 62 & 294 & 13.2 & 0.043 \\
\hline 61950 & Glycoprotein & 20 & 34 & 162 & 8.0 & 0.042 \\
\hline 85862 & CRKRS protein & 14 & 19 & 84 & 6.0 & 0.027 \\
\hline 87097 & EPS15 homology $(\mathrm{EH})$ domain-containing protein & 20 & 31 & 105 & 5.3 & 0.018 \\
\hline
\end{tabular}


ment. This is a major limitation to studying the biology of rust fungi and, thus far, there is a limited knowledge of molecular mechanisms at stake during rust proliferation in planta and, particularly, at the late stage of infection when sporulation occurs. In order to show that physiological heterogeneity and metabolic zonation occurred within fungal tissues (Cairney and Burke 1996), we used an LCM-based approach to study gene expression at the uredinial stage of rust infection in plant tissue (i.e., production of asexual urediniospores) targeting different leaf areas below uredinial structures. Using this strategy, we were able to separate two contrasted fungal tissues from poplar leaf tissues infected by M. larici-populina: a biotrophic area in the plant mesophyll and a sporulation area below the abaxial epidermis where the uredinial dome is formed and from which newly formed urediniospores are released.

Transcriptome analyses strongly depend on RNA quality (Copois et al. 2007) and the use of LCM-collected samples to accurately determine integrity of RNA isolated from microdissected tissues. Low-volume automated electrophoresis bioanalyzers now allow assessment of RNA profiles at very low concentrations, down to $100 \mathrm{pg} / \mu \mathrm{l}$. In microdissection studies, RNA quality is often based on RT-PCR transcript amplification (Kerk et al. 2003; Inada and Wildermuth 2005; Yu et al. 2007) and not on total RNA profiles. Tissue preparation prior to LCM and fixation methods, for instance, can strongly impact quality of RNA (Kerk et al. 2003). Farmer's fixation has been reported to maintain good histological and RNA integrity (Kerk et al. 2003; Ivashikina et al. 2003; Nakazono et al. 2003; Ramsay et al. 2004; Nakada et al. 2006). Loss of RNA integrity during slide mounting was previously pointed out and resolved by the use of a tape transfer system (Cai and Lashbrook 2006). Here, we report that other factors impact RNA quality during tissue preparation, such as sample impregnation and slide mounting. Low-melting paraffin coupled with a direct transfer of paraffin ribbons onto microscope slides without water and slide drying led to a drastic increase of RNA integrity (Fig. 3).

Transcriptome analysis of LCM-sampled tissues revealed gene networks of $M$. larici-populina associated with particular biological features of this rust fungus such as biotrophy and sporulation. Many transcripts were strongly induced in the biotrophic tissues compared with the sporulation tissues, suggesting that the corresponding proteins might be specifically involved in the parasitic growth (Tables 1 and 2). A striking result is the massive induction of genes encoding SSP in the palisade mesophyll, including several homologs of $M$. lini haustorially expressed secreted protein (Catanzariti et al. 2006). These SSP represent a reservoir of putative effectors that might be required to alter the host defense system (Ellis et al. 2007). Thus, it is tempting to link the induction of M. larici-populina SSP to the maintenance of the biotrophic interaction (i.e. through suppression of host defense) at the uredinial stage. Concomitantly with this massive induction of transcripts encoding SSP, the sec3 subunit of the exocyst complex, involved in the tethering, docking, and fusion of post-Golgi vesicles with the plasma membrane (Wu et al. 2008) as well as the Got1-like vesicle transport protein, showed consistent inductions in the fungal tissue (Table 1), suggesting that the exocytosis mechanism, one of the suggested routes for effector secretion (Voegele et al. 2009), might be required for SSP release by rust infection structures. Several transcripts related to car-

Table 2. Most highly upregulated Melampsora larici-populina transcripts in the palisade mesophyll (area 3) versus sporogenous (area 1) microdissected structures identified using whole-genome expression oligoarrays and ranked by decreasing fold changes

\begin{tabular}{|c|c|c|c|c|c|c|c|c|c|c|}
\hline \multirow[b]{3}{*}{ Protein ID $^{b}$} & \multirow[b]{3}{*}{$\mathbf{S P}^{\mathbf{c}}$} & \multirow[b]{3}{*}{ Length } & \multirow[b]{3}{*}{ Cysteine $^{d}$} & \multirow[b]{3}{*}{ Putative function or features } & \multirow[b]{3}{*}{ Blastp $^{e}$} & \multicolumn{5}{|c|}{ Uredinia laser capture microdissection ${ }^{a}$} \\
\hline & & & & & & \multicolumn{3}{|c|}{ Expression level } & \multicolumn{2}{|c|}{ Expression ratio } \\
\hline & & & & & & Area1 & Area2 & Area3 & Area3/Area1 & $P$ \\
\hline 106078 & $\mathrm{Y}$ & 137 & 11 & Rust-specific SSP & PGTG_15874 & 23 & 4,804 & 9,025 & 397.5 & 0.013 \\
\hline Mlp0002_0042 & $\mathrm{Y}$ & 76 & 1 & Mlp-specific SSP & No significant hit & 11 & 517 & 3,802 & 340.4 & 0.012 \\
\hline 106150 & $\mathrm{Y}$ & 118 & 1 & Mlp-specific SSP & No hits found & 28 & 3,457 & 7,441 & 262.1 & 0.012 \\
\hline 104758 & - & 136 & 0 & Mlp-specific protein & No hits found & 19 & 804 & 4,909 & 255.8 & 0.013 \\
\hline 123218 & $\mathrm{Y}$ & 210 & 6 & SSP & PGTG_02151 & 68 & 7,025 & 17,338 & 254.9 & 0.011 \\
\hline 105547 & $\mathrm{Y}$ & 206 & 1 & Mlp-specific SSP & No hits found & 28 & 1,349 & 6,440 & 231.8 & 0.013 \\
\hline 108588 & - & 109 & 4 & Mlp-specific protein & No hits found & 23 & 3,575 & 5,265 & 225.6 & 0.014 \\
\hline 109323 & - & 142 & 3 & Mlp-specific protein & No hits found & 32 & 2,668 & 6,840 & 215.0 & 0.013 \\
\hline 123731 & $\mathrm{Y}$ & 184 & 2 & Mlp-specific SSP & No significant hit & 27 & 1,417 & 5,769 & 212.8 & 0.011 \\
\hline Mlp0016_0150 & $\mathrm{Y}$ & 98 & 7 & Mlp-specific SSP & No significant hit & 18 & 820 & 3,662 & 202.1 & 0.011 \\
\hline 112715 & $\mathrm{Y}$ & 142 & 9 & Mlp-specific SSP & No hits found & 33 & 2,788 & 6,355 & 190.9 & 0.021 \\
\hline 56132 & - & 155 & 4 & Rust-specific protein & PGTG_05628 & 27 & 130 & 5,186 & 189.5 & 0.018 \\
\hline 123531 & $\mathrm{Y}$ & 103 & 9 & Mlp-specific SSP & No significant hit & 41 & 2,966 & 7,457 & 179.8 & 0.040 \\
\hline 60448 & $\mathrm{Y}$ & 156 & 3 & Mlp-specific SSP & No hits found & 48 & 978 & 8,533 & 179.4 & 0.013 \\
\hline 72983 & $\mathrm{Y}$ & 220 & 8 & SSP & PGTG_06969 & 102 & 10,925 & 16,923 & 166.1 & 0.027 \\
\hline 102036 & $\mathrm{Y}$ & 107 & 1 & Mlp-specific SSP & No hits found & 18 & 927 & 2,928 & 165.3 & 0.011 \\
\hline 86274 & $\mathrm{Y}$ & 244 & 10 & SSP & PGTG_04481 & 16 & 763 & 2,523 & 162.3 & 0.007 \\
\hline 106925 & - & 105 & 10 & Mlp-specific protein & No hits found & 21 & 1,668 & 3,022 & 144.1 & 0.010 \\
\hline Mlp0032_0018 & $\mathrm{Y}$ & 76 & 2 & Mlp-specific SSP & No significant hit & 52 & 3,818 & 7,088 & 136.8 & 0.006 \\
\hline 66715 & $\mathrm{Y}$ & 459 & 2 & Mlp-specific secreted protein & No hits found & 14 & 521 & 1,718 & 119.8 & 0.014 \\
\hline 123438 & $\mathrm{Y}$ & 180 & 11 & Rust-specific SSP & PGTG_08705 & 223 & 15,297 & 25,016 & 112.1 & 0.021 \\
\hline 109567 & $\mathrm{Y}$ & 156 & 2 & Mlp-specific SSP & No hits found & 48 & 976 & 5,287 & 109.1 & 0.046 \\
\hline 64764 & $\mathrm{Y}$ & 154 & 1 & SSP (hesp-376 homology) & No hits found & 15 & 185 & 1,363 & 90.0 & 0.012 \\
\hline 68912 & $\mathrm{Y}$ & 144 & 2 & Mlp-specific SSP & No hits found & 38 & 1,255 & 3,390 & 89.7 & 0.014 \\
\hline 58916 & $\mathrm{Y}$ & 219 & 4 & SSP (hesp-C63 homology) & No hits found & 15 & 246 & 1,247 & 85.7 & 0.010 \\
\hline
\end{tabular}

${ }^{a}$ Normalized transcript levels in area 1, 2, and 3 (i.e., spores and sporogenous hyphae, fungal infection tissues in spongy mesophyll, and fungal infection tissues in palisade mesophyll, respectively), transcript expression ratio (area 3/area 1), and associated $t$ test $P$ value $(<0.05)$.

${ }^{\mathrm{b}}$ Protein ID number of corresponding best predicted gene model in the M. larici-populina JGI genome sequence; Mlp0002_0042, Mlp0016_0150, and Mlp0032_0018 correspond to additional predicted gene models not described on the M. larici-populina genome portal.

${ }^{c}$ Signal peptide (SP) prediction. Presence (Y) or absence (-) of a signal peptide is indicated.

d Number of cysteines.

$\mathrm{SSP}=$ small secreted protein .

e Best blast hit against the genome sequence of Puccinia graminis f. sp. tritici deposited at the Broad Institute genome portal. 
bohydrate transport and metabolism and expressed in haustoria of $U$. fabae were also detected in the biotrophic area of $M$. larici-populina. The strong expression of a secreted invertase, a $\beta$-glycosidase, and an hexose transporter ( $U$. fabae HXT1 homolog) is consistent with the hypothesis that fungal enzymes should be present in the haustorial matrix to provide the substrate for the hexose transporter (Voegele et al. 2001, 2006, 2009). In addition, transcripts encoding an amino acid permease showing homology with the haustoria-specific Uf-AAT2 permease (Hahn et al. 1997) were also strongly induced, suggesting a conserved role for rust transporters in nutrient uptake from infected host cells.

Most recent biochemical and molecular studies of rust fungi focused on the parasitic growth and, more precisely, the haustorial structure. In addition, the molecular basis underlying the sporulation process in rust is poorly known. This step is essential for rust development and leads to huge production of asexual urediniospores disseminated by winds over very large distances (Nagarajan and Singh 1990; Barrès et al. 2008). In ascomycetes, molecular genetic approaches have been successfully applied to dissect the genetic mechanisms controlling conidia morphogenesis in model fungal species (Adams et al. 1998). In rust fungi, LCM and EST sequencing of uredinia formed by Phakopsora pachyrhizi identified a limited number of unisequences displaying similarities to known proteins in databases (Tremblay et al. 2009). Among them, transcripts encoding ribosomal protein and serine/threonine-protein phosphatase were also strongly expressed in $M$. larici-populina uredinia. Our LCM-based transcriptome study allowed the unraveling of essential functions of rust sporulation in the basidiomycete $M$. larici-populina (Tables 3 and 4). Asexual urediniospores are the result of cell division occurring via mitosis. Several genes preferentially expressed in the sporulation area are involved in the cell cycle, such as the $M$ phase inducer phosphatase cdc25, as well as cdc45 required for initiation of DNA replication in Saccharomyces cerevisiae (Saha et al. 1998). This mitotic activity during sporogenesis is also supported by transcript induction of a septin involved in cytokinesis. Although cytokinesis mechanisms have been well described during yeast division and sporulation (Wolfe and Gould 2005; Diamond et al. 2009) and hyphae septation (Walther and Wendland 2003), their role in sporogenesis of basidiomycetes remains unclear. The transport mechanisms used to translocate metabolites from haustoria to urediniospores also remains to be determined. We report the strong induction of several transporters that likely play an important role in metabolite trafficking toward the newly formed urediniospores. Peroxidases and superoxide dismutases are involved in the prevention of oxidative damages (Alscher et al. 2002). At later stages of compatible interaction between poplar leaves and Melampsora rust fungi, previous studies have shown the late expression of plant defense-related proteins and the accumulation of reactive oxygen species (Duplessis et al. 2009; Boyle et al. 2010). High levels of detoxification enzyme-related transcripts in the sporulation area could indicate that the fungus is setting protective mechanisms against late plant host defenses. In contrast with the biotrophic area, several transcripts involved in the degradation of plant cell wall polysaccharides were expressed in the sporulation area. The release of a cocktail of degrading enzymes by $M$. larici-populina during sporulation might be required to alter the host cell wall in order to break the epidermis cell layer and release the urediniospores.

In summary, this LCM-transcriptomic-coupled study allowed us to distinguish the metabolic and developmental functions of two contrasted rust tissues at the uredinial stage: a biotrophyrelated tissue in the host palisade mesophyll and a sporulationrelated tissue below the abaxial leaf epidermis. Optimization of LCM technical conditions allowed us to isolate RNA of good integrity to perform an array-based expression analysis. This approach provides insights on distinct genetic programs activated by rust at the uredinial stage. Particularly, a massive induction of transcripts encoding putative effectors, such as SSP, support a late maintenance of biotrophy at the late stage of rust infection, when urediniospores are released. In contrast, cell cycle and cell defense rescue are important components of the rust sporulation process.

\section{MATERIALS AND METHODS}

\section{Growth conditions and inoculation procedures.}

M. larici-populina isolate 98AG31 (pathotype 3-4-7) was used in this study. Urediniospore multiplication and plant inoculation procedures were performed as previously described using the same inoculum of 100,000 urediniospores $/ \mathrm{ml}$, leaf plastochrony index for detached Populus trichocarpa $\times$ P. deltoides 'Beaupré' leaves, and strictly identical culture conditions (Rinaldi et al. 2007). For LCM analysis, leaves were harvested after 168 hpi when uredinial pustules were visible on the leaf abaxial epidermis.

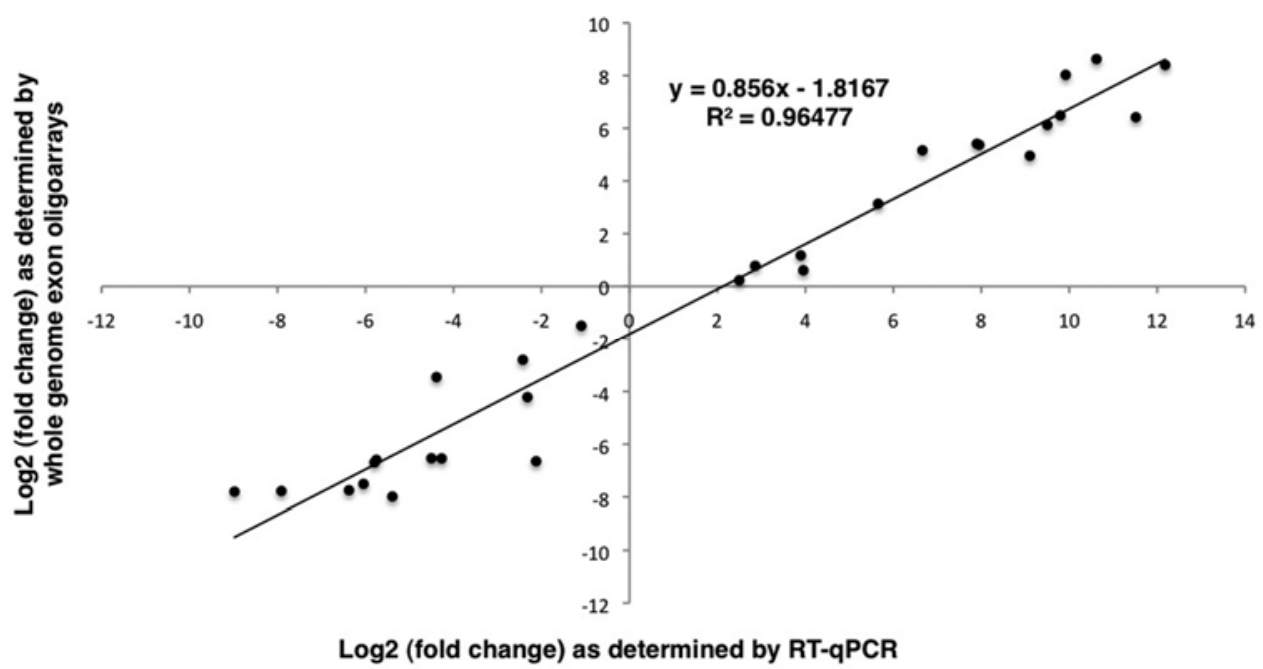

Fig. 4. Validation of Melampsora larici-populina whole genome exon oligoarrays data using reverse-transcription quantitative polymerase chain reaction (RT-qPCR). Log2 transcript fold changes measured on NimbleGen oligoarrays and by RT-qPCR are plotted for a set of 29 differentially-expressed genes between area 3 and area 1. 


\section{Laser-scanning confocal microscopy.}

Infected leaves showing the first fungal decoloration and mature uredinia were harvested at 96 and 168 hpi, respectively, and were directly cut and fixed in $4 \%$ (wt/vol) paraformaldehyde in phosphate-buffered saline (PBS, $\mathrm{pH} 7$ ) for $3 \mathrm{~h}$ at $4^{\circ} \mathrm{C}$. Fixed tissues were washed in PBS buffer $(1 \times)$ and embedded in $6 \%$ agarose (wt/vol). Sections of $20 \mu \mathrm{m}$ were prepared using a VT1000S Leica vibratome (Leica Microsystems, Nanterre, France). Sections were dual stained with $1 \%$ (wt/vol) Uvitex 2B (Polysciences, Eppelheim, Germany) in PBS for 2 min and washed with propidium iodide (PI; $10 \mu \mathrm{g} / \mathrm{ml}$ ) (Invitrogen, Cergy Pontoise, France). PI was used to stain fungal infection structures (Koh et al. 2005) and Uvitex was used to stain plant and fungal cell walls. Transversal sections were observed using a NIKON-BIORAD Radiance 2100 Rainbow confocal scanning laser microscope. Sections were excited with blue laser beams at $405 \mathrm{~nm}$, scanned with a filter setting at 500 to $560 \mathrm{~nm}$ for Uvitex, excited with argon laser beams at $515 \mathrm{~nm}$, and scanned with filter settings at 550 to $650 \mathrm{~nm}$ for PI. Merged images were obtained using the LaserSharp 2000 program (Bio-Rad, Marnes la Coquette, France).

\section{Tissue preparation for LCM.}

Ten leaf pieces of $0.4 \mathrm{~cm}^{2}$, each containing a single uredinium, were randomly sampled on the overall leaf surface and immediately fixed on ice in Farmer's solution (EAA) containing $75 \%(\mathrm{vol} / \mathrm{vol})$ ethanol and $25 \%(\mathrm{vol} / \mathrm{vol})$ acetic acid (Kerk et al. 2003). This fixative was first vacuum infiltrated into the section $(400 \mathrm{~mm}$ of $\mathrm{Hg}$ ) for $15 \mathrm{~min}$ and then left in contact with leaf pieces overnight at $4^{\circ} \mathrm{C}$. Farmer's solution was removed and samples were dehydrated in a graded series of ethanol (45 min each on ice [vol/vol] at 75,80 , and $90 \%$ and three times in absolute ethanol), followed by an ethanol:otix+ (Microm Microtech, Francheville, France) series (45 min each on ice [ $\mathrm{vol} / \mathrm{vol}]$ at $75: 25,50: 50$, and $25: 75 \%$ and three times in $100 \%$ Otix+). After Otix+ removal, two paraffins were used for sample impregnation. The first was a diawax paraffin (Diapath, Martinengo, Italy) with a $58^{\circ} \mathrm{C}$ melting point and the sec-

Table 3. Selected Melampsora larici-populina genes presenting transcript induction in sporogenous (area 1) versus palisade mesophyll (area 3) microdissected structures, assessed by whole-genome expression oligoarrays and categorized according to their cellular category (Functional Catalogue)

\begin{tabular}{|c|c|c|c|c|c|c|}
\hline \multirow[b]{3}{*}{ Protein ID $^{b}$} & \multirow[b]{3}{*}{ Putative function or features } & \multicolumn{5}{|c|}{ Uredinia laser capture microdissection $^{\mathrm{a}}$} \\
\hline & & \multicolumn{3}{|c|}{ Expression level } & \multicolumn{2}{|c|}{ Expression ratio } \\
\hline & & Area1 & Area2 & Area3 & Area1/Area3 & $P$ \\
\hline & Cell rescue, defense and virulence & & & & & \\
\hline 72564 & Cytosolic $\mathrm{Cu} / \mathrm{Zn}$ superoxide dismutase & 6,548 & 173 & 33 & 196.8 & 0.020 \\
\hline 87334 & Peroxidase, family 2 & 7,075 & 487 & 39 & 181.6 & 0.034 \\
\hline 72563 & Cytosolic $\mathrm{Cu} / \mathrm{Zn}$ superoxide dismutase & 5,662 & 1,102 & 59 & 96.4 & 0.046 \\
\hline 94172 & Peroxidase & 6,961 & 3,624 & 81 & 86.2 & 0.046 \\
\hline \multirow[t]{3}{*}{76380} & Cytochrome P450 & 401 & 126 & 11 & 37.3 & 0.013 \\
\hline & Metabolism & & & & & \\
\hline & Lipid & & & & & \\
\hline 94543 & Squalene synthase & 985 & 348 & 11 & 86.7 & 0.022 \\
\hline 59333 & Phospholipase/lecithinase/hemolysin & 2,393 & 645 & 40 & 60.4 & 0.045 \\
\hline 123933 & Epoxide hydrolase & 3,162 & 2,553 & 81 & 39.2 & 0.016 \\
\hline 123555 & Coesterase/carboxylesterase & 646 & 472 & 14 & 45.7 & 0.007 \\
\hline 35173 & Sphingomyelin phosphodiesterase & 554 & 372 & 17 & 32.3 & 0.025 \\
\hline \multirow[t]{2}{*}{63115} & Lipase & 608 & 120 & 20 & 31.1 & 0.014 \\
\hline & Carbon & & & & & \\
\hline 92210 & $\alpha$-Glycosidase (glycoside hydrolase family 71 ) & 700 & 101 & 13 & 55.7 & 0.019 \\
\hline 116147 & $\beta$-Glycosidase (glycoside hydrolase family 5 ) & 2,919 & 1,197 & 55 & 52.8 & 0.044 \\
\hline 55983 & $\beta$-Glycosidase (glycoside hydrolase family 16 ) & 2,246 & 717 & 48 & 47.1 & 0.046 \\
\hline 107307 & $\alpha$-L-arabinofuranosidases (glycoside hydrolase family 51 ) & 1,197 & 1,125 & 35 & 33.9 & 0.021 \\
\hline \multirow[t]{2}{*}{87698} & Chitin deacetylase (carbohydrate esterase family 4) & 907 & 112 & 29 & 31.1 & 0.010 \\
\hline & Nucleotide & & & & & \\
\hline 117154 & Ribonuclease $\mathrm{P}$ protein subunit & 2,665 & 1,312 & 12 & 214.4 & 0.010 \\
\hline 88931 & Adenosine deaminase-like protein & 629 & 23 & 13 & 49.1 & 0.010 \\
\hline 26899 & Endonuclease III & 393 & 105 & 9 & 45.9 & 0.009 \\
\hline 54248 & Ribonuclease & 831 & 189 & 19 & 44.4 & 0.032 \\
\hline \multirow[t]{2}{*}{93485} & Spermidine synthase & 471 & 467 & 11 & 41.4 & 0.013 \\
\hline & Redox & & & & & \\
\hline \multirow[t]{2}{*}{38530} & Oxidoreductase, short chain dehydrogenase & 3,257 & 336 & 13 & 252.9 & 0.010 \\
\hline & Cell cycle and DNA processing & & & & & \\
\hline 40080 & Centrin 3 & 2,308 & 1,741 & 22 & 103.1 & 0.023 \\
\hline 87088 & Septin & 3,232 & 119 & 35 & 92.5 & 0.013 \\
\hline 110193 & 6-O-methylguanine-DNA methyltransferase & 2,253 & 623 & 25 & 89.1 & 0.024 \\
\hline 91152 & 20S cyclosome subunit & 857 & 168 & 11 & 75.5 & 0.009 \\
\hline 76389 & Meiotic chromosome segregation protein & 1,067 & 284 & 23 & 46.1 & 0.014 \\
\hline 71714 & Nuclear transcription factor & 512 & 640 & 14 & 35.5 & 0.022 \\
\hline 85106 & Cell division control protein 45 & 312 & 98 & 9 & 33.8 & 0.026 \\
\hline 30176 & M-phase inducer phosphatase & 638 & 42 & 19 & 33.0 & 0.047 \\
\hline \multirow[t]{2}{*}{89448} & Transcription-associated recombination protein & 397 & 91 & 12 & 31.8 & 0.038 \\
\hline & Cellular transport, transport facilitation & & & & & \\
\hline 49361 & GDP-fucose transporter & 1,119 & 21 & 12 & 93.0 & 0.024 \\
\hline 79553 & ER-Golgi vesicle-tethering protein & 2,865 & 527 & 33 & 86.9 & 0.021 \\
\hline 39514 & Synaptobrevin & 625 & 73 & 10 & 64.4 & 0.013 \\
\hline
\end{tabular}

\footnotetext{
${ }^{a}$ Normalized transcript levels in area 1,2, and 3 (i.e., spores and sporogenous hyphae, fungal infection tissues in spongy mesophyll, and fungal infection tissues in palisade mesophyll, respectively), transcript expression ratio (area 1/area 3), and associated $t$ test $P$ value $(<0.05)$.

${ }^{\mathrm{b}}$ Protein ID number of corresponding best gene model in the M. larici-populina JGI genome sequence.
} 
ond had a $37^{\circ} \mathrm{C}$ melting point (VWR, Fontenay sous bois, France). Samples were transferred to an oven at 37 or $58^{\circ} \mathrm{C}$ and approximately $10 \mathrm{ml}$ of liquefied paraffin (VWR) was added to each vial and left at 37 or $58^{\circ} \mathrm{C}$ overnight. The paraffin was replaced five times at 1.5 -h intervals. Then, samples were embedded using the conventional diawax paraffin with the $58^{\circ} \mathrm{C}$ melting point. This high-melting-point paraffin was retained for tissue embedding in order to realize proper sections. Sections $(10 \mu \mathrm{m}$ each) were cut on a rotary microtome and transferred to microscope membrane slide (Zeiss, Bernried, Germany) with or without water bath impregnation of paraffin ribbons. In order to improve adhesion between microscope slide and ribbons, slides were kept at $45^{\circ} \mathrm{C}$ during $15 \mathrm{~min}$ to spread out ribbons and stored at $-20^{\circ} \mathrm{C}$ in darkness under dehydrating conditions. Just before LCM, slides were deparaffinized twice in Otix+ for $10 \mathrm{~min}$ and then in otix+:ethanol series (3 min each [vol/vol] at 67:33, 50:50, and 33:67\% and three times in absolute ethanol).
LCM.

For each biological replicate, 100 sites of uredinium formation were isolated after sectioning of 10 uredinia randomly sampled from a single infected poplar leaf (10 serial sections per uredinium). For each of the 100 uredinia sections, three distinct areas were collected by LCM at each uredinial site corresponding to spores and sporogenous hyphae, fungal infection tissues in spongy mesophyll, and fungal infection tissues in palisade mesophyll (Fig. 2). A PALM Robot-Microbeam system (Carl Zeiss MicroImaging, Munich, Germany) was used to microdissect cells from deparaffinized and dried tissue sections. Laser parameters for dissection performed with the $\times 40$ objective lens were energy, 52; delta, 12; and focus, 68 using the RoboLPC cutting and catapulting function. The catapulted material was collected in an adhesive cap of a 500- $\mu$ l tube (Zeiss). Three biological replicates were analyzed in total (i.e., three leaves from different poplar plants independently infected by rust urediniospores) and three areas were LCM collected from each replicate.

Table 3. (continued from preceding page)

\begin{tabular}{|c|c|c|c|c|c|c|}
\hline \multirow[b]{3}{*}{ Protein ID $^{\mathbf{b}}$} & \multirow[b]{3}{*}{ Putative function or features } & \multicolumn{5}{|c|}{ Uredinia laser capture microdissection $^{a}$} \\
\hline & & \multicolumn{3}{|c|}{ Expression level } & \multicolumn{2}{|c|}{ Expression ratio } \\
\hline & & Area1 & Area2 & Area3 & Area1/Area3 & $P$ \\
\hline & Cellular transport, transport facilitation (continued) & & & & & \\
\hline 71469 & Aquaporin-1 & 8,125 & 1,313 & 143 & 56.6 & 0.049 \\
\hline 94938 & Permease-MFS transporter & 710 & 461 & 15 & 48.2 & 0.015 \\
\hline 46095 & Endosomal membrane protein & 811 & 113 & 20 & 40.6 & 0.044 \\
\hline 32963 & Vacuolar assembly/sorting protein & 1,578 & 865 & 39 & 40.2 & 0.023 \\
\hline 33903 & Translocation protein & 1,263 & 273 & 34 & 37.3 & 0.027 \\
\hline 49500 & Amino acid permease & 585 & 129 & 16 & 35.7 & 0.031 \\
\hline 94692 & Oligopeptide transporter 4 & 312 & 28 & 10 & 31.8 & 0.041 \\
\hline \multirow[t]{2}{*}{25355} & Permease-MFS transporter & 410 & 34 & 13 & 31.2 & 0.020 \\
\hline & Transcription & & & & & \\
\hline 32431 & Methyltransferase & 1,211 & 774 & 16 & 74.7 & 0.011 \\
\hline 48934 & Ribosomal RNA assembly protein & 2,092 & 1,298 & 30 & 70.5 & 0.010 \\
\hline 50186 & Elongation factor-type GTP-binding protein & 3,359 & 2,787 & 51 & 65.7 & 0.021 \\
\hline 25365 & Glutamyl-tRNA amidotransferase & 728 & 393 & 14 & 52.0 & 0.030 \\
\hline 117808 & tRNA methyltransferase & 1,222 & 177 & 29 & 41.7 & 0.014 \\
\hline 27169 & tRNA methyltransferase complex subunit Cpd1 & 612 & 762 & 17 & 35.2 & 0.008 \\
\hline 38981 & Transcription factor $\mathrm{C} 2 \mathrm{H} 2$ type & 1,059 & 35 & 32 & 33.3 & 0.028 \\
\hline \multirow[t]{2}{*}{75483} & ATP-dependent RNA helicase & 1,441 & 209 & 48 & 30.3 & 0.013 \\
\hline & Cell fate & & & & & \\
\hline 73052 & Expansin/rare lipoprotein A domain protein & 2,384 & 166 & 41 & 58.1 & 0.023 \\
\hline 55582 & Riboflavin aldehyde-forming enzyme/Rare lipoprotein A domain protein & 3,761 & 308 & 67 & 56.5 & 0.037 \\
\hline 70937 & Expansin/rare lipoprotein A domain protein & 3,015 & 1,735 & 81 & 37.4 & 0.035 \\
\hline \multirow[t]{2}{*}{76387} & Expansin/rare lipoprotein A domain protein & 6,249 & 518 & 207 & 30.1 & 0.019 \\
\hline & Protein fate (folding, modification, destination) & & & & & \\
\hline 123605 & Carboxypeptidase S1 & 2,270 & 698 & 31 & 73.5 & 0.029 \\
\hline 92176 & COP9 signalosome complex subunit & 1,003 & 165 & 21 & 48.7 & 0.036 \\
\hline \multirow[t]{2}{*}{76645} & TPR repeat-containing protein & 1,327 & 324 & 41 & 31.3 & 0.038 \\
\hline & Protein synthesis & & & & & \\
\hline 71776 & Ribosomal protein & 1,042 & 98 & 12 & 84.0 & 0.010 \\
\hline \multirow[t]{2}{*}{96447} & Capsular associated protein & 1,538 & 796 & 34 & 45.2 & 0.040 \\
\hline & Energy & & & & & \\
\hline 110853 & NADH-ubiquinone oxidoreductase & 5,248 & 1,767 & 74 & 70.7 & 0.023 \\
\hline \multirow[t]{2}{*}{38407} & FAD monooxygenase & 384 & 340 & 12 & 31.9 & 0.027 \\
\hline & Subcellular localization & & & & & \\
\hline 33341 & Small secreted protein containing CFEM domain (hesp-178 homology) & 2,558 & 328 & 58 & 44.3 & 0.039 \\
\hline \multirow[t]{2}{*}{117611} & GPI transamidase subunit & 319 & 369 & 9 & 36.5 & 0.010 \\
\hline & Cellular communication/signal transduction mechanism & & & & & \\
\hline 117612 & Ankyrin repeat protein & 1,579 & 521 & 38 & 41.0 & 0.026 \\
\hline \multirow[t]{2}{*}{40575} & Ras-related GTPase & 551 & 350 & 18 & 31.3 & 0.011 \\
\hline & Transposable elements, viral and plasmid proteins & & & & & \\
\hline \multirow[t]{2}{*}{72990} & Transposase & 1,280 & 705 & 32 & 40.4 & 0.012 \\
\hline & Protein with binding function or cofactor requirement & & & & & \\
\hline 104398 & Cold-shock DNA/RNA-binding protein & 881 & 625 & 23 & 38.6 & 0.040 \\
\hline \multirow[t]{2}{*}{77832} & Nuclear cap-binding protein subunit & 477 & 241 & 15 & 31.7 & 0.020 \\
\hline & Unclassified proteins & & & & & \\
\hline 117548 & fmHP & 1,950 & 575 & 24 & 80.3 & 0.018 \\
\hline 85991 & Pentatricopeptide (PPR) repeat-containing protein & 2,097 & 109 & 35 & 60.4 & 0.016 \\
\hline 95993 & Major allergen TRI14 & 954 & 197 & 20 & 47.5 & 0.032 \\
\hline
\end{tabular}




\section{RNA extraction and amplification.}

For the LCM experiment, total RNA ( $<5 \mathrm{ng}$ ) was isolated from all samples using the PicoPure RNA isolation kit (Arcturus, Mountain View, CA, U.S.A.). The RNase-Free DNase Set kit (Qiagen, Courtaboeuf, France) was used during the RNA isolation procedure according to the manufacturer's instructions to remove traces of genomic DNA. Elution was performed with $12 \mu \mathrm{l}$ of prewarmed DEPC water $\left(65^{\circ} \mathrm{C}\right)$. Quality and quantity of RNA samples were assessed using the Bio-Rad Experion analyzer and Experion RNA high-sense analysis kit (Bio-Rad). Total RNA from each sample ( $<5 \mathrm{ng}$ ) was subjected to two rounds of amplification using the MessageAmp II aRNA amplification kit (Ambion, Austin, TX, U.S.A.) following the manufacturer's instructions. RNA amplification generated more than $4 \mu \mathrm{g}$ of aRNA for each sample, and aRNA profiles were verified using the Experion analyzer and Experion RNA standard-sense analysis kit (Bio-Rad).

\section{Exon oligoarray analyses.}

The M. larici-populina custom-exon expression array $(4 \times$ 72 K) manufactured by Roche NimbleGen Systems Limited (Madison, WI, U.S.A.) contained four independent, nonidentical, 60-mer probes per gene model coding sequence. In total, 17,556 predicted genes from $M$. larici-populina gene catalog (JGI Melampsora portal) and 1,063 random 60-mer control probes and labeling controls were included on the array (GEO platform no. GPL10350). Double-stranded cDNA were synthesized from $2.5 \mu \mathrm{g}$ of aRNA using the Superscript Doublestranded cDNA synthesis kit (Invitrogen) according to the NimbleGen user protocol. Single-dye labeling of samples, hybridization procedures, and data acquisition were performed at the NimbleGen facilities (NimbleGen Systems, Reykjavik,
Iceland) following their standard protocol. Microarray probe intensities were quantile normalized across chips and average expression levels were calculated for each gene from the independent probes on the array and were used for further analyses. A transcript was deemed expressed when its signal intensity was threefold higher than the mean signal-to-noise threshold (cut-off value) of 1,063 random oligonucleotide probes present on the array. A Student $t$ test with false discovery rate (Benjamini-Hochberg) multiple testing correction was applied to the data using the ARRAYSTAR software (DNASTAR, Inc. Madison, WI, U.S.A.). Transcripts presenting a threefold change in transcript level $(P$ value $<0.05)$ were considered to be significantly differentially expressed. Data filtering, normalization process, and complete expression datasets are available at the Gene Expression Omnibus (National Center for Biotechnology Information) as series no. GSE21487.

\section{RT-qPCR.}

In order to assess transcript levels by RT-qPCR, specific primers of 29 genes were designed with the Primer 3 and Amplify $3 \mathrm{X}$ programs based on the $M$. larici-populina genome sequence (Supplementary Table 1). Amplified fragments showed a length ranging between 121 and 262 nucleotides. Homology searches against $M$. larici-populina and $P$. trichocarpa genome sequences were performed using the blastn algorithm to verify absence of cross annealing with other $M$. larici-populina transcripts as well as with host plant transcripts. First-strand cDNA was synthesized from $150 \mathrm{ng}$ of aRNA using SuperScript II reverse transcriptase (Bio-Rad) with random primers in a final volume of $20 \mu \mathrm{l}$. cDNA derived from aRNA (1.5 ng) was amplified by qPCR in iQ SYBR Green supermix (Bio-Rad) with $0.3 \mu \mathrm{M}$ specific $5^{\prime}$ and $3^{\prime}$ primers. Amplifications were

Table 4. Most highly upregulated Melampsora larici-populina transcripts in sporogenous (area 1) versus palisade mesophyll (area 3) microdissected structures using whole-genome expression oligoarrays and ranked by decreasing fold changes

\begin{tabular}{|c|c|c|c|c|c|c|c|c|c|c|}
\hline \multirow[b]{3}{*}{ Protein ID $^{\mathbf{b}}$} & \multirow[b]{3}{*}{$\mathbf{S P}^{\mathbf{c}}$} & \multirow[b]{3}{*}{ Length } & \multirow[b]{3}{*}{ Cysteine $^{d}$} & \multirow[b]{3}{*}{ Putative function or features } & \multirow[b]{3}{*}{ Blastp ${ }^{e}$} & \multicolumn{5}{|c|}{ Uredinia laser capture microdissection $^{\mathrm{a}}$} \\
\hline & & & & & & \multicolumn{3}{|c|}{ Expression level } & \multicolumn{2}{|c|}{ Expression ratio } \\
\hline & & & & & & Area1 & Area2 & Area3 & Area1/Area3 & $P$ \\
\hline 38530 & - & 240 & 4 & Oxidoreductase, short chain dehydrogenase & PGTG_01366 & 3,257 & 336 & 13 & 252.9 & 0.010 \\
\hline 85149 & - & 131 & 4 & Mlp-specific protein & No hits found & 5,230 & 6,754 & 23 & 222.6 & 0.032 \\
\hline 112748 & - & 245 & 4 & Mlp-specific protein & No hits found & 5,637 & 2,493 & 26 & 218.9 & 0.022 \\
\hline 117154 & - & 422 & 5 & Ribonuclease $\mathrm{P}$ protein subunit & PGTG_13270 & 2,665 & 1,312 & 12 & 214.4 & 0.010 \\
\hline 72564 & - & 122 & 4 & Cytosolic $\mathrm{Cu} / \mathrm{Zn}$ superoxide dismutase & PGTG_05675 & 6,548 & 173 & 33 & 196.8 & 0.020 \\
\hline 87334 & - & 323 & 5 & Peroxidase, family 2 & PGTG_00594 & 7,075 & 487 & 39 & 181.6 & 0.034 \\
\hline 114474 & - & 371 & 11 & Rust-specific protein & PGTG_07899 & 1,568 & 1,170 & 11 & 149.2 & 0.009 \\
\hline 73728 & - & 81 & 1 & Mlp-specific protein & No hits found & 1,557 & 347 & 11 & 145.5 & 0.009 \\
\hline 76897 & $\mathrm{Y}$ & 185 & 10 & Mlp-specific protein & No hits found & 5,523 & 3,451 & 39 & 140.0 & 0.030 \\
\hline 104937 & $\mathrm{Y}$ & 183 & 9 & Mlp-specific protein & No hits found & 2,650 & 1,282 & 21 & 128.9 & 0.011 \\
\hline 112967 & $\mathrm{Y}$ & 185 & 6 & Mlp-specific protein & No hits found & 4,569 & 2,810 & 44 & 103.4 & 0.044 \\
\hline 40080 & - & 166 & 0 & Centrin 3 & PGTG_06324 & 2,308 & 1,741 & 22 & 103.1 & 0.023 \\
\hline 73760 & - & 92 & 1 & Mlp-specific protein & No hits found & 1,154 & 712 & 11 & 102.0 & 0.010 \\
\hline 55089 & - & 74 & 0 & Mlp-specific protein & No hits found & 4,608 & 478 & 46 & 100.8 & 0.022 \\
\hline 105220 & $\mathrm{Y}$ & 160 & 4 & Mlp-specific protein & No hits found & 1,105 & 22 & 11 & 100.0 & 0.026 \\
\hline 34854 & - & 105 & 4 & Hypothetical protein & PGTG_12203 & 4,042 & 363 & 40 & 100.0 & 0.031 \\
\hline 72563 & $\mathrm{Y}$ & 237 & 5 & Cytosolic $\mathrm{Cu}-\mathrm{Zn}$ superoxide dismutase & PGTG_05675 & 5,662 & 1,102 & 59 & 96.4 & 0.046 \\
\hline 63262 & $\mathrm{Y}$ & 572 & 3 & Mlp-specific protein & No hits found & 1,041 & 982 & 11 & 93.8 & 0.007 \\
\hline 103398 & - & 116 & 3 & Mlp-specific protein & No hits found & 939 & 39 & 10 & 93.3 & 0.030 \\
\hline 71121 & - & 113 & 3 & Mlp-specific protein & No hits found & 1,177 & 1,358 & 13 & 93.2 & 0.014 \\
\hline 67049 & - & 376 & 7 & Rust-specific protein & PGTG_15359 & 995 & 57 & 11 & 93.0 & 0.007 \\
\hline 49361 & - & 486 & 6 & GDP-fucose transporter & PGTG_17642 & 1,119 & 21 & 12 & 93.0 & 0.024 \\
\hline 87088 & - & 369 & 2 & Septin & PGTG_13103 & 3,232 & 119 & 35 & 92.5 & 0.013 \\
\hline 110193 & - & 183 & 1 & 6- $O$-methylguanine-DNA methyltransferase & No hits found & 2,253 & 623 & 25 & 89.1 & 0.024 \\
\hline 57035 & - & 69 & 1 & Mlp-specific protein & No hits found & 1,082 & 2,251 & 12 & 89.1 & 0.008 \\
\hline
\end{tabular}

${ }^{a}$ Normalized transcript levels in area 1, 2 and 3 (i.e., spores and sporogenous hyphae, fungal infection tissues in spongy mesophyll, and fungal infection tissues in palisade mesophyll, respectively), transcript expression ratio (area 1/area 3), and associated $t$ test $P$ value $(<0.05$ ).

${ }^{\mathrm{b}}$ Protein ID number of corresponding best gene model in the $M$. larici-populina JGI genome sequence.

${ }^{\mathrm{c}}$ Signal peptide (SP) prediction. Presence (Y) or absence (-) of a signal peptide is indicated.

${ }^{\mathrm{d}}$ Number of cysteines.

${ }^{\mathrm{e}}$ Best blast hit against the genome sequence of Puccinia graminis f. sp. tritici deposited at the Broad Institute genome portal. 
carried out in triplicate with an MJ-opticon2 DNA engine (Bio$\mathrm{Rad})$. After $3 \mathrm{~min}$ of denaturation, 40 cycles $\left(95^{\circ} \mathrm{C}\right.$ for $15 \mathrm{~s}$ and $60^{\circ} \mathrm{C}$ for $1 \mathrm{~min}$ ) were performed and a melting curve was determined to verify absence of multiple amplifications. $M$. larici-populina transcript expression was normalized to the transcript level of a-tubulin $(M l p-a T U B$, JGI protein ID no. 73137) and elongation factor (Mlp-ELFla, JGI protein ID no. 73378) reference genes using the Pfaffl calculation (Pfaffl 2001).

\section{ACKNOWLEDGMENTS}

We thank D. Le Thiec and D. Cohen for their valuable advice on LCM, B. Pêtre for providing macroscopic pictures of uredinia, and A. Rigal for her help in setting sample impregnation. This work was supported by the Région Lorraine and the Institut National de la Recherche Agronomique (Doctoral Scholarship to S. Hacquard and Junior Scientist Research Grants to S. Duplessis) and the Fabelor and IFR 110 Ecogenomics facilities. The Zeiss P.A.L.M. LCM device was co-funded by the Institut National de la Recherche Agronomique, Région Lorraine, and the Conseil Général 54 The Joint Genome Institute (JGI) is acknowledged for the early access made to the $M$. larici-populina genome sequence. JGI sequencing is supported by the Office of Science of the U.S. Department of Energy under contract no. DE-AC02-05CH11231.

\section{LITERATURE CITED}

Adams, T. H., Wieser, J. K., and Yu, J. H. 1998. Asexual sporulation in Aspergillus nidulans. Microbiol. Mol. Biol. Rev. 62:35-54.

Alscher, R. G., Erturk, N., and Heath, L. S. 2002. Role of superoxide dismutases (SODs) in controlling oxidative stress in plants. J. Exp. Bot. 53:1331-13441.

Balestrini, R., Gomez-Ariza, J., Lanfranco, L., and Bonfante, P. 2007. Laser microdissection reveals that transcripts for five plant and one fungal phosphate transporter genes are contemporaneously present in arbusculated cells. Mol. Plant-Microbe Interact. 20:1055-1062.

Balestrini, R., Gomez-Ariza, J., Klink, V. P., and Bonfante, P. 2009. Application of laser microdissection to plant pathogenic and symbiotic interactions. J. Plant Interact. 4:81-92.

Barrès, B., Halkett, F., Dutech, C., Andrieux, A., Pinon, J., and Frey, P. 2008. Genetic structure of the poplar rust fungus Melampsora laricipopulina: Evidence for isolation by distance in Europe and recent founder effects overseas. Infect. Genet. Evol. 8:577-587.

Boyle, B., Levée, V., Hamel, L. P., Nicole M. P., and Séguin, A. 2010. Molecular and histochemical characterisation of two distinct poplar $\mathrm{Mel}$ ampsora leaf rust pathosystems. Plant Biol. 12:364-376.

Broeker, K., Bernard, F., and Moerschbacher, B. M. 2006. An EST library from Puccinia graminis f. sp. tritici reveals genes potentially involved in fungal differentiation. FEMS (Fed. Eur. Microbiol. Soc.) Microbiol. Lett. 256:273-281.

Brooks, L., Strable, J., Zhang, X., Ohtsu, K., Zhou, R., Sarkar, A., Hargreaves, S., Elshire, R. J., Eudy, D., Pawlowska, T., Ware, D., JanickBuckner, D., Buckner, B., Timmermans, M. C., Schnable, P. S., Nettleton, D., and Scanlon, M. J. 2009. Microdissection of shoot meristem functional domains. PLoS Genet. 5:e1000476. Published online.

Cai, S., and Lashbrook, C. C. 2006. Laser capture microdissection of plant cells from tape-transferred paraffin sections promotes recovery of structurally intact RNA for global gene profiling. Plant J. 48:628-637.

Cairney, J. W. G., and Burke, R. M. 1996. Physiological heterogeneity within fungal mycelia: An important concept for a functional understanding of the ectomycorrhizal symbiosis. New Phytol. 134:685-695.

Casson, S. A., Spencer, M. W., and Lindsey, K. 2008. Laser-capture microdissection to study global transcriptional changes during plant embryogenesis. Methods Mol. Biol. 427:111-120.

Catanzariti, A. M., Dodds, P. N., Lawrence, G. J., Ayliffe, M. A., and Ellis, J. G. 2006. Haustorially expressed secreted proteins from flax rust are highly enriched for avirulence elicitors. Plant Cell 18:243-256.

Catanzariti, A. M., Dodds, P. N., Ve, T., Kobe, B., Ellis, J. G., and Staskawicz, B. J. 2010. The AvrM effector from flax rust has a structured C-terminal domain and interacts directly with the $\mathrm{M}$ resistance protein. Mol. Plant-Microbe Interact. 23:49-57.

Chandran, D., Inada, N., Hather, G., Kleindt, C. K., and Wildermuth, M. C. 2010. Laser microdissection of Arabidopsis cells at the powdery mildew infection site reveals site-specific processes and regulators. Proc. Natl. Acad. Sci. U.S.A. 107:460-465.

Copois, V., Bibeau, F., Bascoul-Mollevi, C., Salvetat, N., Chalbos, P., Bareil, C., Candeil, L., Fraslon, C., Conseiller, E., Granci, V., Mazière,
P., Kramar, A., Ychou, M., Pau, B., Martineau, P., Molina, F., and Del Rio, M. 2007. Impact of RNA degradation on gene expression profiles: Assessment of different methods to reliably determine RNA quality. J. Biotechnol. 127:549-559.

Diamond, A. E., Park, J. S., Inoue, I., Tachikawa, H., and Neiman, A. M. 2009. The anaphase promoting complex targeting subunit Ama1 links meiotic exit to cytokinesis during sporulation in Saccharomyces cerevisiae. Mol. Biol. Cell 20:134-145.

Dodds, P. N., Lawrence, G. J., Catanzariti, A. M., Ayliffe, M. A., and Ellis, J. G. 2004. The Melampsora lini AvrL567 avirulence genes are expressed in haustoria and their products are recognized inside plant cells. Plant Cell 16:755-768.

Duplessis, S., Major, I. T., Martin, F., and Séguin, A. 2009. Poplar and pathogen interactions: Insights from Populus genome-wide analyses of resistance and defense gene families and gene expression profiling. Crit. Rev. Plant. Sci. 28:309-334.

Ellis, J. G., Dodds, P. N., and Lawrence, G. J. 2007. The role of secreted proteins in diseases of plants caused by rust, powdery mildew and smut fungi. Curr. Opin. Microbiol. 10:326-331.

Feau, N., Bergeron, M. J., Joly, D., Roussel, F., and Hamelin, R. 2007. Detection and validation of EST-derived SNPs for poplar leaf rust $\mathrm{Mel}$ ampsora medusae f. sp. deltoidae. Mol. Ecol. Notes 7:1222-1228.

Gérard, P. R., Husson, C., Pinon, J., and Frey, P. 2006. Comparison of genetic and virulence diversity of Melampsora larici-populina populations on wild and cultivated poplar and influence of the alternate host. Phytopathology 96:1027-1036.

Gomez, S. K., and Harrison, M. J. 2009. Laser microdissection and its application to analyze gene expression in arbuscular mycorrhizal symbiosis. Pest. Manage. Sci. 65:504-511.

Hahn, M., and Mendgen, K. 1997. Characterization of in planta-induced rust genes isolated from a haustorium-specific cDNA library. Mol. Plant-Microbe Interact. 10:427-437.

Hahn, M., Neef, U., Struck, C., Göttfert, M., and Mendgen, K. 1997. A putative amino acid transporter is specifically expressed in haustoria of the rust fungus Uromyces fabae. Mol. Plant-Microbe Interact. 10:438-445.

Heath, M. C. 1997. Signalling between pathogenic rust fungi and resistant or susceptible host plants. Ann. Bot. 80:713-720.

Inada, N., and Wildermuth, M. C. 2005. Novel tissue preparation method and cell-specific marker for laser microdissection of Arabidopsis mature leaf. Planta 221:9-16.

Ithal, N., Recknor, J., Nettleton, D., Maier, T., Baum, T. J., and Mitchum, M. G. 2007. Developmental transcript profiling of cyst nematode feeding cells in soybean roots. Mol. Plant-Microbe Interact. 20:510-525.

Ivashikina, N., Deeken, R., Ache, P., Kranz, E., Pommerrenig, B., Sauer, N., and Hedrich, R. 2003. Isolation of AtSUC2 promoter-GFP-marked companion cells for patch-clamp studies and expression profiling. Plant J. 36:931-945.

Jiang, K., Zhang, S., Lee, S., Tsai, G., Kim, K., Huang, H., Chilcott, C., Zhu, T., and Feldman, L. J. 2006. Transcription profile analyses identify genes and pathways central to root cap functions in maize. Plant Mol. Biol. 60:343-363

Kemen, E., Kemen, A. C., Rafiqi, M., Hempel, U., Mendgen, K., Hahn, M., and Voegele, R. T. 2005. Identification of a protein from rust fungi transferred from haustoria into infected plant cells. Mol. Plant-Microbe Interact. 18:1130-1139.

Kerk, N. M., Ceserani, T., Tausta, S. L., Sussex, I. M., and Nelson, T. M. 2003. Laser capture microdissection of cells from plant tissues. Plant Physiol. 132:27-35.

Klink, V. P., Overall, C. C., Alkharouf, N. W., MacDonald, M. H., and Matthews, B. F. 2007. A time-course comparative microarray analysis of an incompatible and compatible response by Glycine max (soybean) to Heterodera glycines (soybean cyst nematode) infection. Planta 226:1423-1447.

Koh, S., André, A., Edwards, H., Ehrhardt, D., and Somerville, S. 2005 Arabidopsis thaliana subcellular responses to compatible Erysiphe cichoracearum infections. Plant J. 44:516-529.

Nagarajan, S., and Singh, D. V. 1990. Long-distance dispersion of rust pathogens. Annu. Rev. Plant Pathol. 28:139-153.

Nakada, M., Komatsu, M., Ochiai, K., Ohtsu, K., Nakazono, M., Nishizawa N. K., Nitta, K., Nishiyama, R., Kameya, T., and Kanno, A. 2006. Isolation of MaDEF from Muscari armeniacum and analysis of its expression using laser microdissection. Plant Sci. 170:143-150.

Nakazono, M., Qiu, F., Borsuk, L. A., and Schnable, P. S. 2003 Laser-capture microdissection, a tool for the global analysis of gene expression in specific plant cell types: Identification of genes expressed differentially in epidermal cells or vascular tissues of maize. Plant Cell 15:583-596.

Pfaffl, M. W. 2001. A new mathematical model for relative quantification in real-time RT-PCR. Nucleic Acids Res. 29:e45.

Puthoff, D. P., Neelam, A., Ehrenfried, M. L., Scheffler, B. E., Ballard, L., Song, Q., Campbell, K. B., Cooper, B., and Tucker, M. L. 2008. Analy- 
sis of expressed sequence tags from Uromyces appendiculatus hyphae and haustoria and their comparison to sequences from other rust fungi. Phytopathology 98:1126-1135.

Ramsay, K., Wang, Z., and Jones, G. K. 2004. Using laser capture microdissection to study gene expression in early stages of giant cells induced by root-knot nematodes. Mol. Plant Pathol. 5:587-592.

Rinaldi, C., Kohler, A., Frey, P., Duchaussoy, F., Ningre, N., Couloux, A., Wincker, P., Le Thiec, D., Fluch, S., Martin, F., and Duplessis, S. 2007. Transcript profiling of poplar leaves upon infection with compatible and incompatible strains of the foliar rust Melampsora larici-populina. Plant Physiol. 144:347-366.

Ruepp, A., Zollner, A., Maier, D., Albermann, K., Hani, J., Mokrejs, M., Tetko, I., Güldener, U., Mannhaupt, G., Münsterkötter, M., and Mewes, H. W. 2004. The FunCat, a functional annotation scheme for systematic classification of proteins from whole genomes. Nucleic Acids Res. 32:5539-5545.

Saha, P., Thome, K. C., Yamaguchi, R., Hou, Z., Weremowicz, S., and Dutta, A. J. 1998. The human homolog of Saccharomyces cerevisiae CDC45. J. Biol. Chem. 273:18205-18209.

Sohn, J., Voegele, R. T., Mendgen, K., and Hahn, M. 2000. High level activation of vitamin B1 biosynthesis genes in haustoria of the rust fungus Uromyces fabae. Mol. Plant-Microbe Interact. 13:629-636.

Tang, W., Coughlan, S., Crane, E., Beatty, M., and Duvick, J. 2006. The application of laser microdissection to in planta gene expression profiling of the maize anthracnose stalk rot fungus Colletotrichum graminicola. Mol. Plant-Microbe Interact. 19:1240-1250.

Thara, V. K., Fellers, J. P., and Zhou, J. M. 2003. In planta induced genes of Puccinia triticina. Mol. Plant Pathol. 4:51-56.

Tremblay, A., Li, S., Scheffler, B. E., and Matthews, B. F. 2009. Laser capture microdissection and expressed sequence tag analysis of uredinia formed by Phakopsora pachyrhizi, the causal agent of Asian soybean rust. Physiol. Mol. Plant Pathol. 6:163-174.

Voegele, R. T., Struck, C., Hahn, M., and Mendgen, K. 2001. The role of haustoria in sugar supply during infection of broad bean by the rust fungus Uromyces fabae. Proc. Natl. Acad. Sci. U.S.A. 98:8133-8138.

Voegele, R. T., Wirsel, S., Möll, U., Lechner, M., and Mendgen, K. 2006.
Cloning and characterization of a novel invertase from the obligate biotroph Uromyces fabae and analysis of expression patterns of host and pathogen invertases in the course of infection. Mol. Plant-Microbe Interact. 19:625-634.

Voegele, R. T., Hahn, M., and Mendgen, K. 2009. The Uredinales: Cytology, Biochemistry, and Molecular Biology. Pages 69-98 in: The Mycota, 5. Plant Relationships Volume. H. B. Deising, ed. Springer, Berlin.

Walther, A., Wendland, J. 2003. Septation and cytokinesis in fungi. Fungal Genet. Biol. 40:187-196.

Wolfe, B. A., and Gould, K. L. 2005. Split decisions: Coordinating cytokinesis in yeast. Trends Cell Biol. 15:10-18.

Wu, H., Rossi, G., and Brennwald, P. 2008. The ghost in the machine: Small GTPases as spatial regulators of exocytosis. Trends Cell Biol. 18:397-404.

Yin, C., Chen, X., Wang, X., Han, Q., Kang, Z., and Hulbert, S. H. 2009. Generation and analysis of expression sequence tags from haustoria of the wheat stripe rust fungus Puccinia striiformis f. sp. tritici. BMC Genomics 10:626.

Yu, Y., Lashbrook, C. C., and Hannapel, D. J. 2007. Tissue integrity and RNA quality of laser microdissected phloem of potato. Planta 226:797803.

\section{AUTHOR-RECOMMENDED INTERNET RESOURCES}

Broad Institute Puccinia Group database: www.broadinstitute.org/annotation/genome/puccinia_group/MultiHome .html

Munich Information Center for Protein sequence (MIPS) functional catalogue: mips.helmholtz-muenchen.de/proj/funcatDB

National Center for Biotechnology Information Gene Expression Omnibus database: www.ncbi.nlm.nih.gov/geo

NimbleGen website: www.nimblegen.com

U.S. Department of Energy JGI genome database queries: genome.jgi-psf.org/Mellp1/Mellp1.home.html and genome.jgi-psf.org/Poptr1_1/Poptr1_1.home.html 